\title{
Living on beyond the body: The digital soul of Black Mirror
}

\author{
Clarissa Carden and Margaret Gibson
}

Griffith University

Carden C., Gibson M. (2021) Living on Beyond the Body: The Digital Soul of Black Mirror. In: Gibson M., Carden C. (eds) The Moral Uncanny in Black Mirror. Palgrave Macmillan, Cham. https://doi.org/10.1007/978-3-030-47495-9 8

Pp 141-152

\section{Introduction}

The desire for immortality is part of the human condition. Tales of immortal beings, and of means through which humans too can cheat death, are part of mythologies worldwide. Great minds have spent lifetimes seeking a cure for death. It is easy, today, to dismiss alchemy and the search for the philosopher's stone as childish nonsense, but it was a quest which occupied kings and scientists alike. Today, our hopes have turned to digital technologies, and the promise of a lengthened - or unending - lifespan. Cultural logics of anti-ageing hold the reality of old age, and by extension, the reality of death, as a 'solvable problem' rather than a natural and potentially positive reality. ${ }^{1}$ As such, the idea that digital technologies may promise a form of immortality has existed for some time. At the present moment, two very different types of immortality have been positioned as possibilities for the near future. The first is the promise that a company may be able to mine the data a person creates in order to produce a facsimile of that person. The company Eternime, currently undertaking beta testing, promises to create an avatar which will be able to chat online and respond as the original would. ${ }^{2}$ In a more controversial effort, the company Nectome is 'committed to the goal of archiving your mind' through downloading human brains to computers. ${ }^{3}$ In order to do this, the person whose mind is downloaded must be euthanised. Nectome's process has not yet been attempted.

Black Mirror, in its typical dystopian style, provides a window into what the world would be like if technologies like these succeeded. Black Mirror is an anthology series, one in which there is no plot which continues from episode to episode. The narratives presented in this show do not conform to a clear timeline, nor do they necessarily share characters. However, several shared technologies and themes tie the series together in a universe which, despite the lack of clear timeline, is clearly shared, a point emphasised by the Season 4 finale Black Museum. The universe in which many of the narratives in Black Mirror unfold is one in which digital immortality has been achieved - it has become possible to replicate an individual's essence - in effect to create or extract a digital soul. Drawing from the evidence in seasons 2-4 of the series, this chapter explores the role and moral status of the digital soul in Black Mirror. 


\section{Digital immortality in Black Mirror}

There are two key forms of digital replication or immortality in Black Mirror. We discuss them here in turn, noting that one is far more prevalent than the other. The first is a digital replication of an individual who has died based on the traces they leave behind online. This form of replication is featured in the Season 2 episode Be Right Back, wherein a bereaved wife takes advantage of technology to create a digital double of her deceased husband, Ash. At first, this digital double is akin to what is already promised by companies such as Eternime. ${ }^{4}$ Drawing from the evidence Ash left behind on social media, it creates a chat program, which can be spoken to through voice or text. Material of this type - the social media pages and other digital footprints left behind by a person who has died - have been described as 'digital remains' ${ }^{5}$ which play an important role in the continuation of ties between the living and the dead. ${ }^{6}$ In this sense, the type of digital afterlife initially represented in Be Right Back is only a step away from the type of digital afterlife any person with an active online presence may experience today.

However, Black Mirror pushes the familiar concept further than can be realistically envisioned with current technologies. In Be Right Back, the same company which offers the chat program also offers something else - a physical replication of the person who has gone, which can be imprinted upon a blank android body and which, it is promised, will hold all of Ash's memories. It is, in essence, a replacement for the original. As Artt notes, "[i]n 'Be Right Back,' technology does not just ease mourning, but tries to circumvent it altogether'. 'The android double of Ash in Be Right Back is not Ash's own pre-planned after-death resurrection but the decision of his bereaved wife who struggles to come to terms with his death.

However, this kind of replication from digital remains is shown to be insufficient. It draws from a public record of the self which is necessarily incomplete. The problem with this digital double - discovered only after it is too late and he is truly created as a physically embodied android, is that it is missing Ash's private self. It is a digital replication, but one without what may be described as the essence or soul of the original. As such, it is necessarily imperfect and unsatisfying.

This type of digital replication is secondary in the Black Mirror universe to the nearubiquitous technology of cookies. Cookies are one of the core technologies in the Black Mirror universe. They are a thinking, feeling, digital replication of an individual. Cookies have the personality and memories of the living, breathing, original of whom they are a double. Like Daniel Gray, the protagonist of Greg Egan's wonderful short story The Extra, ${ }^{8}$ a person who has a cookie made for a specific purpose may be unaware that the process creates a remainder who is, in all significant respects, them, but who is trapped within a reality which prevents them from expressing this.

They also share the embodiment of the original, in the sense that cookies experience themselves and are experienced by other cookies as embodied beings. This is a crucial factor in creating an environment in which cookies can be unaware of their own digital status. In existing virtual environments, the moral weight of digital lives, even as separable from the physical life of the user behind a character, is increased or made more apparent through the construction of an embodied digital self. ${ }^{9}$ In the case of cookies, their recognisable physical embodiment in a digital environment reinforces the conception that their lives are human lives, and blurs the division between the digitised self and the person replicated. 
Despite the digital physicality of cookies, they do not, nonetheless, have a presence in the physical world. A cookie cannot extend beyond the confines of the world created for it. Black Mirror makes clear the vulnerability of cookies to the whims of the - physically present and alive programmers, designers, and users who determine the conditions under which they live. In the Season 2 episode White Christmas and the Season 4 episode USS Callister, the potential for cookies to be intentionally subjected to abuse or torture is made clear. The Season 4 episode Black Museum portrays the extent to which a digitally replicated soul is vulnerable to the failings of programmers. If the replication of Ash in Be Right Back creates a physical presence with no soul, cookies create a digital soul whose lack of physical presence leaves them open to great suffering.

The mechanisms through which cookies are created, and the multi-faceted purposes to which they are employed, varies through the show's seasons. In the Season 4 finale, Black Museum, the viewer learns that the original cookies - the first efforts to replicate a human consciousness in a digital form - could be created only if the original, physical, body was euthanised. In this sense, the cookie is positioned as something akin to the type of digital transference envisioned by real, presentday companies such as Nectome. ${ }^{10}$

In other episodes, however, the use of cookies has clearly developed. They become tools to be used in personal assistance devices, akin to a highly personalised and advanced form of Apple's Siri or Amazon's Alexa, as seen in the Season 2 finale White Christmas, or data to be used in simulations for a dating app, as in the Season 4 episode Hang the DJ. Cookies, although they are not described as such, are shown to be replications which can be constructed based on DNA alone, as in USS Callister. They serve a social good, too, as in the much-lauded Season 3 episode San Junipero, wherein those who have died can experience a digital afterlife as young, healthy, versions of themselves.

Despite the many morally harmful or ambiguous uses of cookies, the technology as it is presented in Black Mirror appears, at first glance, to offer a type of immortality which is distinct from that which appears graspable today. Rather than merely replicating some facets of the self, it appears to replicate the whole soul - to promise, in short, a type of continued existence of the self which may last beyond the final barrier of death. However, all episodes featuring cookies, with the possible exception of San Junipero and Black Museum, the cookie is a digital double rather than a digital transference or extension of the physical self, and thus its experience is not a direct continuation of the experience of the original, who must still eventually die. In the two episodes in which the cookie appears to allow for the continuation of human experience, the mechanics through which this is possible are unclear. Even within San Junipero's positive, joyful exploration of a digital heaven, it seems possible, that the elderly people who plan for an immortal, youthful existence instead gift immortality to another self - one who shares their thoughts, memories, and arguably their core self, but whose experience is not a true continuation of the original's.

Cookies in Black Mirror are so prominent, and used in so many contradictory ways, that

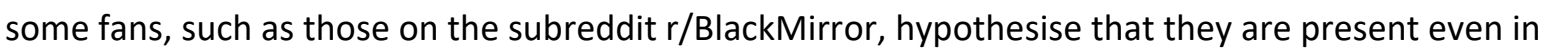
episodes where they are not explicitly mentioned or shown. A key example is the 2018 choose-yourown-adventure film Bandersnatch. Set in the 1980s, Bandersnatch is branded as a Black Mirror special, but its temporal setting renders it unlike the rest of the Black Mirror oeuvre. It follows Stefan, a young game developer who seeks to bring an epic choose-your-own-adventure novel, Bandersnatch, to life as a 64-bit game. In this film, viewers are transformed into active participants, making decisions in an effort to guide Stefan as he inevitably descends into madness. The inconsistency between Bandersnatch and the episodes which have come before it is stark. Nonetheless, there are direct references to familiar episodes, most notably the presence of the 
symbol used in the Season 2 episode White Bear, which features an individual being perpetually punished for a heinous crime.

This symbol, and the prevalence of cookies in other episodes of Black Mirror, has led some fans of Black Mirror to seize on the idea that Stefan is a cookie, programmed to constantly relive the moment when the original Stefan committed a violent murder. In this conceptualisation of Bandersnatch, we - the viewer/player - are implicated in Stefan's torture as viewers all over the world deliver commands which drive him to one of several deeply upsetting endings.

\section{The moral status of the digital soul}

In the Black Mirror universe, technology is never entirely good or benign. The brief and incomplete overview above demonstrates the extent to which digital replications of an individual, whether living or dead, are morally ambiguous at best. Both the android Ash in Be Right Back, who Artt ${ }^{11}$ and Panka ${ }^{12}$ liken to Frankenstein's creation, and the many variations of cookies represented in the series, exist within a monetary economy. That is, they can be purchased, sold, and used.

Significantly, this can occur without the consent, informed or otherwise, of the original person who is replicated. The reference to Mary Shelley's most famous creation is apt and can indeed be extended to both forms of digital replication. Like Victor Frankenstein, the oft-unseen programmers behind Black Mirror's digital replicas take parts of human beings - their consciousness, or their digital remains - and create a form of life which is wholly new. Like Frankenstein, too, they are largely absent as their creations come to terms with their new existence and enter some part of a world which still revolves around the needs and desires of living, breathing, human beings. And, like Frankenstein's pathetic and troubled creation, Black Mirror's digital replications - particularly cookies - gave no consent to being created, fully-formed, in order to advance another's interests.

In our world, longevity is tightly linked to the monetary economy. Those who can afford to pay, in both money and time, for a healthy lifestyle have a significant advantage over those who cannot. When illness strikes, the miracles of modern science and technology can save lives - so long as the bearers of those lives can pay or have the privilege of living in a nation in which their government is willing to pay to prolong their lives. There is nothing new, then, in the conception that one's duration and quality of life is, at least in part, dependent on one's economic status.

Immortality, however, is not part of this economic economy. Depending on one's religious beliefs, it is available to all, to no one, or is allocated on the basis of good works. While mortal life is connected in troubling ways to economic realities, immortal or eternal life has traditionally been linked to moral economies. The authors of this article, while non-religious, were raised within Christian religious traditions - one Protestant, and one Catholic. For our religious communities of origin, the fate of an individual's eternal soul is within their own hands. While monetary wealth may be unevenly and unfairly distributed, moral deeds are not.

Black Mirror offers a depiction of a world in which eternal life becomes subject to the same monetary economy as mortal life. If one's very essence - one's soul - can be extracted and replicated without consent, it becomes a saleable good which can be used and misused. In White Christmas, viewers are faced with the disdain which living human beings may feel toward a digital replica. In this episode, Matt played by Jon Hamm, sells the ultimate digital personal assistant - a device operated by a cookie, which is by its nature perfectly in tune with the user's wants and needs. In order to force the new lifeform to fulfil menial tasks such as making toast and keeping the user's 
calendar, Matt employs a particularly cruel form of torture - he speeds up time, forcing the cookie to experience months or years of utter emptiness, and threatening to repeat the treatment if they do not comply. Toward the end of the episode, he himself suffers as a result of the misuse of cookies, this time by police. A cookie replica of Matt is made to confess to a crime committed by the original. At the conclusion of the episode a police officer casually changes the settings on the device storing the cookie, causing it to experience thousands of years in an empty cabin with a single song blaring. This final action is not required to obtain an outcome or for any other reason. It is a simple and callous act, the consequence of which is to inflict an unthinkable torture on a being which thinks and feels as though it is human.

This science-fiction depiction of the callous disregard for non-human intelligent life is in keeping with more traditional depictions of robots or androids. Non-human, but humanoid, robots are a mainstay of science fiction. These robots, as human-like as they may be, tend to be treated as lesser beings - we are unable to see our own creations as our peers, even as we imagine them to be increasingly like us. ${ }^{13}$ The cookies of Black Mirror literally are us - they are the immortal essence of the original, a product which is akin to the soul of Christian tradition - and yet the fact that they are digital and artificially created rather than naturally born strips them of their moral authority. In Black Mirror, then, the authority to inflict eternal torture or to grant eternal life without suffering is in the hands of human beings. The powers traditionally ascribed to a god or gods thus fall into the hands of the corporation, or the government, or indeed the unknowing original self.

While White Christmas explores the implications of the digital soul falling into the hands of callous figures of authority, it is USS. Callister which most clearly delves into the consequences of human beings taking on a role of infinite power over a digital replica. In this episode, Robert Daly (Jesse Plemons), the Chief Technical Officer of a gaming corporation, feels bullied and belittled in his workplace. He derives control - and revenge - from creating digital replicas of his unknowing colleagues, who he uploads into a unique version of his company's game, Infinity, which has been modified to resemble his favourite show, Space Fleet [a Star Trek parody]. The scenes inside Daly's game are bright, colourful, and nostalgic, invoking the look and feel of the original Star Trek series. However, his colleagues are trapped, held against their will, and forced to act according to Daly's wishes. His control over their lives extends to modifying their bodies, taking away their sexual organs.

There is comedy in the episode - for example, the discovery that Daly had modified her body led the protagonist, Nanette (Cristin Milioti), to say "Stealing my pussy is a red fucking line." Despite this, USS Callister includes one of the darkest moments in the series. Daly's chief real-world antagonist James Walton is the CEO of his company. He was also the first person who Daly replicated and added to the game. Walton reveals that, in order to control him, Daly obtained his son's DNA and replicated him, only to push the virtual child into space. He kept the DNA in his fridge, and was able and willing to torture the child - who, it must be remembered, experienced himself as real - as often as necessary to force Walton to comply. Here, again, the lack of respect for digital lives, and the excessive control resting in the hands of those who have the capacity to harness technology, is emphasised. In USS Callister, the show reminds us that, if we develop the capacity to replicate ourselves, we transform into gods: individuals who may not only be callous - as in White Christmas but also actively vindictive and cruel.

Here, the multiplicity of the digital soul becomes key. Daly is able to construct and reconstruct any member of his digital Space Fleet crew, along with Walton's son. Even if the rules of the environment in which a cookie is placed allow for death or deletion, the replicability of the digital soul means that another cookie, also devoid of choice, may take the place of the original. The 
use of DNA in this way also raise the question of unknowability - in the Black Mirror universe one can go about one's business, blissfully unaware than an exact copy of oneself is being subjected to inhumane treatment. This is indeed the case in USS Callister, where Daly's colleagues in the physical world have no sense of the existence of their digital doubles.

A final example of the problematic moral status of cookies in Black Mirror comes from one of Season 4's most positive episodes, Hang the DJ. At first, this appears to be the story of two individuals - Amy (Georgina Campbell) and Frank (Joe Cole) - who live in a tightly controlled world dictated by a system enforced by something called Coach, which forces them to enter predetermined relationships for pre-determined lengths of time. The ultimate aim of this system, they are told, is to pair each person with their perfect match. Neither Amy nor Frank has any memories of being anywhere other than in their current environment, and their only knowledge of the outside world is that there is something threatening beyond the walls that surround them. Towards the middle of the episode, Frank suggests that they are living in a simulation - a suggestion Amy laughs off, but which becomes more real to her as she notices small inconsistencies in her environment. When Amy is told that her perfect partner has been determined, she is permitted to meet Frank to say goodbye. They escape together, only to find themselves surrounded by other Franks and Amys. A screen announces that the simulation has been run 1000 times, with 998 escapes - meaning that the real Frank and Amy are $99.8 \%$ compatible. The protagonists of the episode are deleted, along with their 997 escaped doubles. The episode ends with the real, physically embodied, couple meeting in a bar.

Hang the $D J$ is, in some ways, a cute love story. The episode is positioned between Crocodile and Metalhead, two of Season 4's bleakest episodes. Despite its charm, however, it again raises the moral problem of the way in which cookies are used. The Frank and Amy the viewers follow through the episode are people with real personalities, real thoughts, feelings, and hopes. Their experiences, including their eventual escape, lead their originals to meet and presumably to fall in love. However, their own erasure, immediately upon taking the - to them - impossibly brave step of running away together, discounts their own moral status and indicates that their lives and feelings are immaterial. A form of life which, in Black Mirror's other love story, San Junipero, is treated as real and legitimate is, in Hang the $D J$, afforded no greater moral status than one might grant to a video game character.

\section{Moral implications}

Science fiction has the potential to predict and contribute to pressing moral questions. Debates over the moral status of artificial intelligence are by now well-established, and consider such questions as whether artificial lifeforms can be considered moral agents, what responsibilities they might have, what we may owe to intelligent creations, and how we, as humans, are able to respond to artificial life. ${ }^{14}$ Researchers are also working to explore the way in which machines can be taught to make moral decisions, given the fact that morality itself is culturally relative. ${ }^{15}$ However, before the emergence of the extensive body of work presently addressing this question, science fiction narratives - most notably Isaac Asimov's landmark work $I$, Robot, sparked public consideration of what it would mean to live alongside intelligent artificial life. These questions, once abstract, are now pressing with the rapid advance of artificial intelligence, which, while it has not reached the point of replicating human beings, is nonetheless becoming capable of taking on complex tasks like 
driving, within which are embedded sticky moral questions.

The technologies represented in Black Mirror are, as yet, the work of fantasy. Despite the promises of start-ups which seek to produce a type of immortality, there is not yet any convincing evidence that even technologies of the more modest type depicted in Be Right Back are likely to become part of our daily realities in the near future. This does not, however, render the considerations raised by Black Mirror irrelevant. As we stated at the outset of this article, technologies are already in the works which seek to address immortality through means which correspond to the two main forms of immortality described in Black Mirror. Despite the very early phase of this work, it is likely that someone, at some point, will find a way to construct a reasonable facsimile of a person who was once alive and now has died. Public writings discussing emerging or promising technologies which seek to replicate life tend to use Black Mirror as a cultural touchstone through which to explain or explore the implications of such developments. ${ }^{16}$ Black Mirror, in exploring complex moral questions through its trademark style that is simultaneously bleak and satiric, prompts us to consider the moral implications of the creation of the digital soul before it comes to be a real issue that is before us.

In an era in which data leaks are common and the ownership of the texts, images, and films which one posts online are often unclear, the call to be protective and considerate of our digital data is well-worn. However, the forms of information we project into the world are increasing - a trend for family research has given private corporations access to vast quantities of DNA and extensive information about kinship networks, while platforms like Facebook, Twitter, and Instagram encourage us to share ourselves - or a version of ourselves - with the world. Black Mirror asks us to consider what it would mean if, rather than simply parts or projections of ourselves, our data actually was us. It is an issue we may one day have to face. 
1 John A. Vincent, "Ageing Contested: Anti-Ageing Science and the Cultural Construction of Old Age," Sociology 40, no. 4 (August 2006): 694, https://doi.org/10.1177/0038038506065154.

2 "Eternime."

3 "Nectome."

4 "Eternime."

5 Jessa Lingel, "The Digital Remains: Social Media and Practices of Online Grief," The Information Society 29, no. 3 (May 2013): 190-95, https://doi.org/10.1080/01972243.2013.777311; Patrick Stokes, "Deletion as Second Death: The Moral Status of Digital Remains," Ethics and Information Technology 17, no. 4 (December 2015): 237-48, https://doi.org/10.1007/s10676-015-9379-4.

${ }^{6}$ B. Carroll and K. Landry, "Logging On and Letting Out: Using Online Social Networks to Grieve and to Mourn," Bulletin of Science, Technology \& Society 30, no. 5 (October 1, 2010): 341-49, https://doi.org/10.1177/0270467610380006; M. Gibson, "Death and Mourning in Technologically Mediated Culture," Health Sociology Review: The Journal of the Health Section of the Australian Sociological Association 16, no. 5 (December 2007): 415; Margaret Gibson, "Automatic and Automated Mourning: Messengers of Death and Messages from the Dead," Continuum 29, no. 3 (May 4, 2015): 33953, https://doi.org/10.1080/10304312.2015.1025369.

7 "'An Otherness That Cannot Be Sublimated': Shades of Frankenstein in Penny Dreadful and Black Mirror," Science Fiction Film \& Television 11, no. 2 (June 2018): 272, https://doi.org/10.3828/sfftv.2018.18.

8 “The Extra," eidolon.net, 1990, http://www.eidolon.net/?story=The\%20Extra.

${ }^{9}$ Margaret Gibson and Clarissa Carden, Living and Dying in a Virtual World: Digital Kinships, Nostalgia and Mourning in Second Life, Palgrave Macmillan Memory Studies (Palgrave Macmillan, 2018).

10 "Nectome."

11 "'An Otherness That Cannot Be Sublimated."

12 "Transparent Subjects: Digital Identity in Mary Shelley's Frankenstein and Charlie Brooker's 'Be Right Back,'” Science Fiction Studies 45, no. 2 (2018): 308, https://doi.org/10.5621/sciefictstud.45.2.0308.

${ }^{13}$ Min-Sun Kim and Eun-Joo Kim, "Humanoid Robots as 'The Cultural Other': Are We Able to Love Our Creations?," AI \& SOCIETY 28, no. 3 (August 2013): 309-18, https://doi.org/10.1007/s00146-012-0397-z.

${ }^{14}$ Hutan Ashrafian, "Artificial Intelligence and Robot Responsibilities: Innovating Beyond Rights," Science and Engineering Ethics 21, no. 2 (April 2015): 317-26, https://doi.org/10.1007/s11948-014-9541-0; Bartosz Brożek and Bartosz Janik, "Can Artificial Intelligences Be Moral Agents?," New Ideas in Psychology, January 2019, https://doi.org/10.1016/j.newideapsych.2018.12.002; Kim and Kim, "Humanoid Robots as 'The Cultural Other.'”

${ }^{15}$ Edmond Awad et al., "The Moral Machine Experiment," Nature 563, no. 7729 (November 2018): 59-64, https://doi.org/10.1038/s41586-018-0637-6.

${ }^{16}$ e.g. Courtney Humphries, "Digital Immortality: How Your Life's Data Means a Version of You Could Live Forever," MIT Technology Review, 2018, https://www.technologyreview.com/s/612257/digital-versionafter-death/. 